\title{
Uso do Custeio por Absorção e do Sistema RKW para gerar informações gerenciais: Um estudo de caso em hospital
}

\author{
Ilse Maria Beuren \\ Doutorado em Controladoria e Contabilidade pela Faculdade de Economia, \\ Administração e Contabilidade da Universidade de São Paulo - FEA/USP \\ Professora da Universidade Regional de Blumenau- FURB \\ Rua Antônio da Veiga, B.Victor Konder, 140. Blumenau/SC. CEP: 89012-900 \\ E-mail: ilse@furb.br
}

Nair Fernandes Schlindwein Mestrado em Administração pela Fundação Universidade Regional de Blumenau -

FURB

Rua Amazonas, 30. Ribeirão Fresco. Blumenau/SC. CEP: 89020-900

E-mail: nair.schlindwein@gmail.com

\section{RESUMO}

A apuração e o controle dos custos são relevantes para qualquer organização, com destaque para as organizações hospitalares, que enfrentam usualmente limitações em relação aos recursos disponíveis, uma vez que essas informações são vitais para a sua adequada gestão. A literatura aponta com frequência vantagens do uso de diferentes sistemas de custos para organizações de serviço e especialmente de saúde, sem, contudo, ter validado esses modelos em uma organização hospitalar completa e identificado seus reais e efetivos benefícios. Nesse sentido, o objetivo deste estudo é demonstrar o uso do custeio por absorção aliado ao sistema RKW para gerar informações gerenciais em uma organização hospitalar, dispensando assim um sistema paralelo de custeio e os custos a ele relacionados para atendimento dos preceitos legais. A pesquisa foi conduzida a partir de análise documental e de uma entrevista no mês de novembro de 2007 com o responsável da área de custos do hospital. Face às descobertas da pesquisa e à luz da literatura, pode-se concluir que o sistema tradicional por absorção aliado ao sistema RKW permite apurar os custos dos procedimentos hospitalares com precisão aceitável, sendo importante instrumento de gestão.

Palavras-chave: Custos. Sistemas de custos. Custeio por absorção. RKW.

\section{Use of Absorption Costing and the RKW system for generating managerial information: A hospital based case study}

\section{ABSTRACT}

Monitoring and controlling costs are relevant matters to any organization, especially hospitals which usually encounter limitations in relation to available resources, as this 
Uso do Custeio por Absorção e do Sistema RKW para gerar informações gerenciais: Um estudo de caso em hospital Ilse Maria Beuren, Nair Fernandes Schlindwein

information is vital to successful management. The literature frequently points to the advantages of using different cost systems for service organizations, especially those involved in the health care industry, although these models have not been validated in a complete hospital organization, nor have their real and effective benefits been identified. As such, the objective of this study is to demonstrate the use of absorption costing joined with the RKW system for generating managerial information in a hospital organization, thus making use of a parallel system of costing and costs and thereby relating them to fulfillment of legal precepts. The research was conducted starting with an interview held in November 2007 with the person responsible for hospital costs, followed by documental analysis. In light of the discoveries of the research and review of the literature it can be concluded that the traditional absorption system joined with the RKW system allows for monitoring of costs of hospital procedures with an acceptable level of precision, and is an important instrument in management.

Keywords: Costs. Cost systems. Absorption costing. RKW.

\section{INTRODUÇÃO}

As organizações hospitalares são consideradas como ambientes complexos em virtude da multidisciplinaridade de profissionais que nelas atuam e pela divergência de objetivos. Isto pode ser exemplificado pelos objetivos dos gestores em obter equilíbrio econômico-financeiro a partir da recuperação dos custos e maximização do superávit (receita maior que despesa); das equipes assistenciais (médicos, enfermeiros, farmacêuticos, nutricionistas, fisioterapeutas, etc.) em prover a melhor assistência possível independente do custo a ela relacionado; dos acionistas, no caso de instituições particulares, na maximização do lucro, entre outros. A complexidade do ambiente hospitalar pode ser compreendida a partir dos interesses dispersos dos grupos de relação, bem como do processo decisório não linear e em rede em função dos diversos níveis de influência destes grupos.

De acordo com a Organização Panamericana de Saúde (OPAS, 2004), as organizações hospitalares são definidas como um sistema de saúde formado por pessoas e entidades cujo objetivo principal é melhorar as condições de saúde da população. Além disso, é um local para atendimento de casos complexos de doenças, onde, consequentemente, são realizados procedimentos de maior custo e que consomem elevados níveis de insumos, manutenção e investimentos. 
Uso do Custeio por Absorção e do Sistema RKW para gerar informações gerenciais: Um estudo de caso em hospital Ilse Maria Beuren, Nair Fernandes Schlindwein

A função essencial das organizações hospitalares é a assistência à saúde, ou seja, a prestação de serviços à população, o que implica inevitavelmente em elevado custo de pessoal. Porém, neste ambiente, outros custos significativos à estrutura hospitalar podem ser identificados como: de materiais, medicamentos e manutenção. Okazaki e Escrivação Jr. (2007) alertam que os sucessivos aumentos nos gastos da saúde e que preocupam governo, empresas contratantes da assistência à saúde, operadoras de planos de saúde e beneficiários, são geralmente explicados com o envelhecimento da população e os avanços tecnológicos ligados aos materiais e medicamentos. No entanto, podem esconder também ineficiências da gestão hospitalar.

Para os autores, as financiadoras do sistema, como governos e operadoras, estabelecem auditorias sobre os gastos hospitalares e negociam formas de remuneração que incluem o compartilhamento dos riscos. Esta prática pode ser identificada no reembolso pelo sistema de "pacote" que independe dos insumos utilizados no tratamento do paciente ou na quantidade de dias que o mesmo permaneceu internado, sendo o valor pré-estabelecido e único. De acordo com este modelo, todo excesso de consumo é arcado pelo próprio hospital.

Este compartilhamento de risco e de controle rigoroso de custos foi motivado pelo desequilíbrio financeiro advindo da publicação da Lei no. 9.656/98, que obrigou as operadoras de planos de saúde a ampliarem suas coberturas e a cobrirem todos os custos de procedimentos antes limitados. Adicionalmente, proibiu qualquer tipo de exclusão ou de exceção e limitou o reajuste dos planos individuais, que passou a ser controlado pela Agência Nacional de Saúde (ANS).

Por conseguinte, os hospitais passaram a demandar um controle acurado de custos para garantir sua competitividade no mercado, mantendo os níveis de investimento necessários à prática da medicina moderna. Em pesquisa realizada por Okazaki e Escrivação Jr. (2007) com quatro grandes hospitais de São Paulo, as equipes assistenciais, compostas principalmente por médicos, não consideram o custo na escolha do material. Esta situação é reforçada, por um lado, pela formação puramente assistencial destas equipes, enquanto de outro lado, sofrem pressões das 
Uso do Custeio por Absorção e do Sistema RKW para gerar informações gerenciais: Um estudo de caso em hospital Ilse Maria Beuren, Nair Fernandes Schlindwein

operadoras para uso de materiais mais baratos, independente da qualidade do mesmo, podendo causar prejuízos aos pacientes e desperdícios ao sistema de saúde.

A complexidade das organizações hospitalares, com seus vários conflitos de objetivos, requer a geração de informações sobre custos que representem ao máximo e em detalhe a realidade do ambiente hospitalar, de forma que se possa conhecer seus custos e gerenciá-los. Embora a eficiência administrativa e financeira dos hospitais esteja relacionada diretamente com o uso eficaz dos recursos disponíveis (Muccini; Bruni e Mac-Allister, 2006), segundo pesquisa realizada por Abbas (2001), grande parte das organizações hospitalares não faz uso de um sistema de custo que forneça parâmetros para a tomada de decisão ou o fazem de forma precária.

A apuração e o controle de custos é uma necessidade para qualquer organização, inclusive as hospitalares, pois o primeiro servem para o controle da gerência e o acompanhamento dos serviços prestados, e permitem a implantação de medidas corretivas que visam melhorar o desempenho da organização. Assim, conhecer e controlar o verdadeiro custo dos serviços e o valor de cada atividade tornase um diferencial competitivo (Struett; Souza e Raimundini, 2006).

Entretanto, a qualidade das informações de custos de uma organização está diretamente ligada ao sistema de custos utilizado para gerá-las (Souza et al., 2007). Esta acepção é reforçada por Atkinson et al. (2000) e Anthony e Govindarajan (2002), quando argumentam que a principal contribuição da gestão de custos é assegurar que os recursos sejam obtidos e usados eficazmente. Isso inclui rotinas como medir e registrar resultados das atividades que ocorrem dentro da organização, para assegurar que os tomadores de decisão disponham das informações necessárias para orientar o processo decisório.

No sentido de dispensar um sistema paralelo de custeio e os custos a ele relacionados para atendimento dos preceitos legais, elaborou-se a seguinte questãoproblema: Como pode ser aplicado o custeio por absorção aliado ao sistema RKW para gerar informações gerenciais em uma organização hospitalar? O objetivo deste estudo é demonstrar o uso do custeio por absorção aliado ao sistema RKW para gerar informações gerenciais em uma organização hospitalar, dispensando assim um sistema 
Uso do Custeio por Absorção e do Sistema RKW para gerar informações gerenciais: Um estudo de caso em hospital Ilse Maria Beuren, Nair Fernandes Schlindwein

paralelo de custeio e os custos a ele relacionados para atendimento dos preceitos legais. A pesquisa foi conduzida a partir de análise documental e de uma entrevista no mês de novembro de 2007 com o responsável da área de custos do hospital e de análise documental.

O trabalho está estruturado em cinco seções, iniciando com essa introdução. $\mathrm{Na}$ sequência se apresenta o referencial teórico, com ênfase na abordagem do custeio por absorção ou tradicional, do Reichskuratorium für Wirtschaftlichkeit (RKW), do custeio por absorção aliado ao custeio RKW e do custeio alvo ou target cost. Em seguida se descreve a metodologia utilizada na pesquisa. Após se apresenta a descrição e análise do estudo de caso e conclusões do estudo realizado.

\section{REERENCIAL TEÓRICO}

A contabilidade de Custos e a Gestão de Custos surgiram como uma evolução da contabilidade financeira desenvolvida durante o advento do Mercantilismo e que se sustentou até a Revolução Industrial no século XVIII. Estava centrada na apuração do estoque, ou seja, o Custo das Mercadorias Vendidas (CMV) era determinado através da verificação dos estoques e das compras do período (Martins, 2003)

O impacto decorrente do avanço tecnológico nos processos produtivos implicou maior controle e gestão de custos e sua correta apropriação ao produto, de forma a garantir a manutenção da competitividade da organização no mercado. Neste contexto, os sistemas de custos foram desenvolvidos para fornecer informações que auxiliem no processo decisório e que evoluíram juntamente com as mudanças tecnológicas e a adoção de novas formas de administração (Souza; Clemente, 1998).

Abbas (2001) menciona que o sistema de custo deve gerar informações úteis para o planejamento, controle e tomada de decisão. Esta visão é compartilhada por Frega, Lemos e Souza (2007) que argumentam que a gestão estratégica de custos, amparada pelas informações fornecidas pelos sistemas de controle, monitora o comportamento da estratégia implementada na organização. De acordo com os autores, os sistemas de custos promovem alterações comportamentais dos indivíduos 
Uso do Custeio por Absorção e do Sistema RKW para gerar informações gerenciais: Um estudo de caso em hospital Ilse Maria Beuren, Nair Fernandes Schlindwein

cujas atividades estão sendo medidas, criando uma consciência maior sobre os pontos críticos dos processos.

Vários são os métodos de custeio desenvolvidos pela contabilidade de custos, como: o tradicional método de custeio por absorção, o custeio variável, o custeio baseado em atividades (Activity Based Costing- $A B C$ ) e o $A B C$ induzido pelo tempo (Time Driven Activity Based Costing). Ainda, qualquer um desses métodos pode ter associado o custeio meta (Target costing) na definição do custo máximo aceitável dado uma restrição de preços.

Frega, Lemos e Souza (2007) comentam em sua pesquisa que o custeio clássico por absorção é ainda o mais amplamente utilizado como único sistema de custeio, motivado principalmente por ser instituído por força da legislação e pelas restrições de recursos que seriam demandados para a implantação de um sistema de custeio paralelo.

Souza et al. (2007) indicam organizações hospitalares como fortes candidatas a implantar com sucesso o $A B C$. No entanto, não se tem verificado na literatura a descrição de um caso de sucesso de aplicação deste sistema de custeio em uma organização hospitalar inteira, limitando-se a validá-lo em setores ou unidades operacionais (Abbas, 2001; Struett, Souza e Raimundini, 2006; Dalmácio, Rezende e Aguiar, 2006; Souza et al., 2007).

Uma das principais críticas à aplicação integral do sistema $A B C$ tradicional é apresentada na pesquisa de Dalmácio, Rezende e Aguiar (2006). Os autores identificaram no modelo original a utilização da premissa de que os recursos são totalmente utilizados (100\% da capacidade), o que significa que as taxas dos direcionadores de custos são mais elevadas do que a utilização real.

Embora a literatura seja farta em ressaltar os benefícios da aplicação do sistema de custeio baseado em atividades ( $A B C)$, o índice de implantação deste modelo ainda é baixo. De acordo com Kaplan e Anderson (2004), a resistência na implantação do modelo é justificada pela dificuldade e complexidade na identificação dos direcionadores das diversas atividades que compõem as operações da organização. 
Uso do Custeio por Absorção e do Sistema RKW para gerar informações gerenciais: Um estudo de caso em hospital Ilse Maria Beuren, Nair Fernandes Schlindwein

Para melhorar estas limitações os autores adaptaram o modelo original e criaram um modelo que denominaram Custeio Baseado em Atividades ( $A B C$ ) induzido pelo tempo (Time Drivem ABC Model). Kaplan e Anderson (2004) argumentam que o tempo é de fato o único direcionador de custos das atividades, o que simplificaria o processo de identificação dos direcionadores de custo.

Entre as adaptações sugeridas por Kaplan e Anderson (2004) estão: a) a estimativa do custo por unidade de tempo da capacidade, considerando que na prática esta equivale entre 70 a $80 \%$ da capacidade teórica plena; b) estimativa dos tempos unitários das atividades; c) derivação dos direcionadores de custo; d) análise e apresentação dos custos; e, e) atualização do modelo sempre que uma nova atividade for agregada à operação, bastando estimar o tempo desta atividade.

Um dos pontos-chave do Time Driven ABC é que permite avaliar o tempo ocioso, ou seja, o tempo disponível e não gasto com a execução de atividades. Esse modelo apresenta as seguintes características: a) utilização do conceito de custo-padrão para a determinação da taxa padrão; b) identificação das atividades com capacidade ociosa; c) possibilidade de mensuração dos recursos gastos com as atividades, considerando o tempo de execução; d) determinação dos valores gastos com cada atividade, levando em consideração as ociosidades de cada departamento e/ou atividade (Kaplan; Anderson, 2004).

O principal diferencial do sistema de custeio por atividades induzido pelo tempo é a análise da capacidade instalada ou teórica com a capacidade utilizada, propiciando a avaliação da eficiente produtiva de cada centro de atividades (Dalmácio, Rezende e Aguiar, 2006), o que pode ser considerado uma informação relevante para orientação do processo decisório estratégico. Entretanto, Matos (2008) questiona a facilidade na apuração prática do tempo utilizado para realização das atividades.

Em organizações hospitalares, fortemente afetadas por restrições de recursos e pelo aumento no custo derivado principalmente do desenvolvimento de novas tecnologias em materiais, medicamentos e equipamentos, faz-se necessário um controle rigoroso dos custos que assegure a continuidade do funcionamento destas 
Uso do Custeio por Absorção e do Sistema RKW para gerar informações gerenciais: Um estudo de caso em hospital Ilse Maria Beuren, Nair Fernandes Schlindwein

organizações de forma que atendam sua função social sem perda da qualidade do serviço prestado. Todavia, Abbas (2001) e Struett,

Souza e Raimundini (2006) indicam que o uso de sistemas de custeio adequados ainda é incipiente no meio hospitalar.

Na sequência, com vista no foco do presente estudo, faz-se uma incursão teórica no custeio por absorção, também denominado de tradicional, e no custeio Reichskuratorium für Wirtschaftlichkeit $(\mathrm{RKW})$. Além disso discorre-se sobre a integração de ambos os métodos e faz-se uma abordagem do custeio meta ou custeio alvo.

\subsection{Custeio por absorção ou tradicional}

O custeio por absorção é um método desenvolvido a partir da aplicação dos conceitos básicos da contabilidade clássica e que consiste na apropriação de todos os custos de produção aos produtos produzidos, assim como todos os demais gastos relativos ao esforço aplicado na produção (Martins, 2003). Este método implica na separação de custos e despesas e a consequente apropriação dos custos indiretos, por meio de rateio, aos produtos, assim como seus custos diretos (Kaplan; Cooper, 1998).

Horngren, Foster e Datar (2000, p. 331) justificam a alocação dos custos indiretos devido ao fato de representarem considerável proporção dos custos totais atribuídos aos objetos de custeio. Citam quatro objetivos da alocação de custos indiretos aos objetos de custeio: "a) fornecer informação para decisões econômicas; b) motivar administradores e empregados; c) justificar custos ou calcular reembolsos; e, d) mensurar o lucro e os ativos para os relatórios destinados ao público externo".

A alocação dos custos indiretos e diretos não precisa satisfazer simultaneamente a todos esses objetivos. Custos distintos podem ser alocados de forma diferente em vista dos objetivos pretendidos. No caso de fornecer informação para decisões econômicas, como determinação de preço, devem ser considerados os custos da cadeia de valor completa. Por sua vez, para motivar administradores e empregados, frequentemente são considerados os custos de diversas atividades que interagem, a 
Uso do Custeio por Absorção e do Sistema RKW para gerar informações gerenciais: Um estudo de caso em hospital Ilse Maria Beuren, Nair Fernandes Schlindwein

fim de ressaltar como os custos dessas atividades se relacionam (Horngren; Foster; Datar, 2000).

De acordo com Souza et al. (2007), o grande problema deste método de custeio está na determinação dos critérios de rateio aplicados, assim como na dedução das despesas diretamente do resultado. Esta dualidade do sistema pode criar situações dúbias ou mesmo mascarar resultados de acordo com a apropriação dos custos e despesas. Pode apresentar um lucro menor, interessante do ponto de fiscal do Imposto de Renda, para organizações com fins lucrativos. Por outro lado, pode apresentar um lucro majorado para instituições que tenham interesse em apresentar resultados positivos, ou cujos administradores tenham participação no resultado.

Entretanto, este sistema de custeio é utilizado obrigatoriamente pela legislação brasileira, com algumas exceções (Martins, 2003, p.42). Esta situação de obrigatoriedade força as organizações, caso desejarem implantar um outro sistema de custeio, a adotá-lo de forma paralela. Além das dificuldades iniciais incorridas em qualquer implantação de uma nova metodologia de trabalho, esse aspecto torna-se uma barreira, considerada a necessidade de aumento dos recursos disponíveis para a manutenção de dois sistemas de custeio.

Nas instituições hospitalares o sistema de custeio por absorção ainda é amplamente utilizado, embora seja criticado na literatura por não fornecer informações adequadas para subsidiar o processo decisório. Para Struett, Souza e Raimundini (2006), o sistema tradicional nestas organizações trata o custo do paciente-dia de forma linear e assim apresenta-se inadequado para a tomada de decisão, devendo os sistemas possibilitar a mensuração do custo dos serviços e a análise das variações destes custos.

\subsection{Reichskuratorium für Wirtschaftlichkeit (RKW)}

Conhecido também como o precursor do sistema Activity Based Costing (ABC), este sistema foi difundido no Brasil e aplicado conjuntamente ao sistema tradicional de custeio por absorção. Desenvolvido na Alemanha, o Reichskuratorium für 
Uso do Custeio por Absorção e do Sistema RKW para gerar informações gerenciais: Um estudo de caso em hospital Ilse Maria Beuren, Nair Fernandes Schlindwein

Wirtschaftlichkeit (RKW), consiste não só do rateio dos custos de produção, como também de todas as despesas da organização (Martins, 2003).

Segundo Bornia (2002), este método trata somente de custos de transformação, portanto, não contempla matérias-primas e outros materiais diretos. Para fins de apropriação desses custos divide a empresa em centros de custos. Assim os custos são alocados aos centros de custos por meio de bases de distribuição, e esses são alocados aos produtos por meio de critérios de utilização desses recursos. Destaca ainda que os centros de custos podem ser determinados considerando-se: "o organograma (cada setor da empresa pode ser um centro de custos), a localização (quando partes da empresa se encontram em localidades diferentes, cada local pode ser um centro), as responsabilidades (cada gerente pode ter sob sua responsabilidade um centro de custos) e a homogeneidade" (Bornia, 2002, p. 101).

De acordo com Mattos (2001), este sistema permite que cada centro de custo transfira seu custo total, por meio de rateio, a todos os centros de custo que tenham prestado serviços, através de uma sequência hierarquizada dos centros de custo. Portanto, centros de custo que já tenham sido rateados não receberão novos rateios, evitando assim a formação de resíduos de custos não apropriáveis aos produtos.

A operacionalização do método de custeio RKW é sintetizada por Bornia (2002, p. 103) em cinco fases: "a) separação dos custos em itens; b) divisão da empresa em centros de custos; c) identificação dos custos com os centros (distribuição primária); d) redistribuir os custos dos centros indiretos até os diretos (distribuição secundária); e) distribuição dos custos dos centros diretos aos produtos (distribuição final) ".

Esse ciclo completo de rateio dos custos pressupõe o objetivo de se chegar ao custo final do objeto de custeio. No entanto, para fins de análise e controle dos custos podem ser importantes também as etapas intermediárias de alocação dos custos conforme preconizado por esse método. Portanto, o gestor pode estruturar o sistema de modo que consiga extrair informações nas fases intermediárias, de acordo com as necessidades do processo decisório. 
Uso do Custeio por Absorção e do Sistema RKW para gerar informações gerenciais: Um estudo de caso em hospital Ilse Maria Beuren, Nair Fernandes Schlindwein

\subsection{0 custeio por absorção aliado ao custeio RKW}

Shank e Govindarajan (1997, p. 14) criticam o atual enfoque dos esforços voltados para a gestão de custos. Explicam que "gerenciar custos com eficácia exige um enfoque amplo, externo à empresa". Esse enfoque na cadeia de valor concebem como o "conjunto de atividades criadoras de valor desde as fontes de matérias-primas básicas, passando por fornecedores de componentes e até o produto final entregue nas mãos do consumidor".

Ressaltam que hoje o enfoque é, em grande parte, interno à empresa, com ênfase em "suas compras, seus processos, suas funções, seus produtos e seus consumidores". Entendem que isso representa um enfoque de valor agregado, em que se busca maximizar a diferença entre compras e vendas.

Portanto, o conceito de cadeia de valor é distinto do conceito de valor agregado. A crítica de Shank e Govindarajan (1997) ao enfoque do valor agregado é que a gestão de custos inicia tarde e termina cedo demais. Mencionam que iniciar a análise de custos com as compras pode excluir oportunidades de explorar relacionamentos comerciais com os fornecedores da empresa. Por outro lado, os autores ressaltam que diversas oportunidades da gestão de custos são desperdiçadas por não se considerar o impacto no final da cadeia de valor, devido ao fato de encerrar a análise de custos cedo demais. Ambas as situações proporcionariam maior competitividade à organização se fosse reconhecida a cadeia de valor.

Segundo Horngren, Sundem e Stratton (2004), a ênfase dos sistemas de custeio tradicionais (o custeio por absorção e o custeio variável) está nas atividades operacionais. Em outras palavras, o enfoque desses sistemas está centrado no valor agregado. Os autores entendem que o Activity Based Costing tem a vantagem de não apenas custear as atividades operacionais, mas também as demais atividades que compõem a cadeia de valor. No entanto, é mais complexo quando comparado aos sistemas de custeio tradicionais, o que dificulta sua implantação.

O custeio por absorção é apresentado por Bornia (2002) em duas vertentes: custeio por absorção integral ou total e custeio por absorção ideal. No custeio por absorção integral todos os custos de produção incorridos são alocados aos objetos de 
Uso do Custeio por Absorção e do Sistema RKW para gerar informações gerenciais: Um estudo de caso em hospital Ilse Maria Beuren, Nair Fernandes Schlindwein

custeio, portanto, atende as exigências da contabilidade financeira em relação à avaliação de estoque, embora também possa ser utilizado para fins gerenciais. No custeio por absorção ideal também os custos de produção incorridos são alocados aos objetos de custeio, mas com a exclusão dos desperdícios (custos relacionados com insumos usados de forma ineficiente). Portanto, auxilia no controle dos custos e no processo de gestão de melhoria contínua da empresa.

Aliando-se o método de custeio Reichskuratorium für Wirtschaftlichkeit (RKW) ao custeio por absorção consegue-se maior acurácia na apropriação dos custos indiretos, se comparado com a utilização isolada do custeio por absorção, principalmente em decorrência da divisionalização da organização em centros de custos. Os rateios acontecem de forma similar ao custeio por absorção, mas direcionados para centros de custos e posteriormente são alocadas aos objetos de custeio. Aliando-se o custeio por absorção ideal em detrimento do custeio por absorção integral haveria uma maior aproximação ao enfoque da cadeia de valor, porque seria possível identificar desperdícios, por exemplo, oriundos de compra de materiais a preços menores, mas de qualidade inferior.

O presente estudo propõe aliar o custeio por absorção integral ao RKW, uma vez que essa combinação atende aos usuários externos e também auxilia os gestores da organização hospitalar, mesmo que o enfoque seja o de agregação de valor e não o da cadeia de valor.

Essa alternativa foi considerada pelo fato de implicar na existência de apenas um sistema de custos para diferentes finalidades e parece prudente dado a complexidade na apuração dos custos hospitalares. Mesmo que o trabalho não explore a utilização do custeio meta ou custeio alvo, ele deve ser considerado na gestão dos custos em função das restrições nos preços dos serviços prestados pelo hospital.

\subsection{Custeio Alvo ou Target Cost}

$\mathrm{Na}$ crescente competitividade enfrentada pelas organizações, o preço do produto é cada vez mais uma função de oferta e demanda. O surgimento do custeio alvo ou meta, ou do inglês target cost, surge como um processo que apresenta o custo máximo 
Uso do Custeio por Absorção e do Sistema RKW para gerar informações gerenciais: Um estudo de caso em hospital Ilse Maria Beuren, Nair Fernandes Schlindwein

de um produto, dado determinado preço de venda e que consiga o mínimo de rentabilidade esperada pela organização (Martins, 2003). Para o autor, o custo meta, apesar do conceito simples, é na verdade uma forma de gestão e uma decisão estratégica. De acordo com Ducati (2006), esta metodologia fornece aos tomadores de decisão elementos para motivar a redução de custos.

Cooper e Slagmulder (1997) ressaltam três características do custeio alvo: a) os custos são determinados ou permitidos pelo mercado; b) este sistema permite integração da empresa com objetivo de atingir os custos permitidos; e c) permite planejar lucros e custos a longo prazo. Sakurai (1997) apresenta outras características, que podem ser consideradas complementares às acima apresentadas: a) o custeio alvo é empregado normalmente na fase de planejamento do produto; b) é utilizado para planejar ou reduzir custos, mas não para controlar; c) é mais adaptável às indústrias; e, d) é um instrumento de controle destinado para orientar a tomada de decisões estratégicas.

De acordo com Rocha et al. (1999), este sistema está fortemente embasado em três premissas básicas: a) o lucro é a garantia da sobrevivência da empresa; b) o custo é definido antes do início da produção; e, c) o custo é fortemente influenciado pela concorrência.

Esta metodologia permite uma visão estratégica das operações da organização e que incluem:

a) usar a capacidade instalada para novos produtos; b) permitir a organização focar as operações eficientes e seus motivadores; c) focar não somente aspectos de redução de custos de uma melhoria, mas buscar compreender a dinâmica relativa à capacidade dessas melhorias; d) buscar aumentar a lucratividade através da redução da mão-de-obra, aumento da fabricação e venda de produtos, venda dos estoques existentes e buscar reduzir a capacidade ociosa para zero; e, e) melhorar o desempenho operacional e financeiro através do acompanhamento completo da execução do custo alvo (Yu-Lee, 2003).

De acordo com Ducati (2006), a principal motivação e vantagem do uso do custeio alvo é a busca por um preço justo ao consumidor, além da constante motivação 
Uso do Custeio por Absorção e do Sistema RKW para gerar informações gerenciais: Um estudo de caso em hospital Ilse Maria Beuren, Nair Fernandes Schlindwein

pela redução do custo do produto. O autor ressalta ainda que este método pode ser utilizado em conjunto com qualquer método de custeio, como o por absorção.

Portanto, o custeio alvo ou target cost deve incluir a pauta do processo decisório dos gestores de organizações hospitalares, independente do método de custeio adotado, devido restrições no estabelecimento de preços, seja por imposição de convênios, por preços de concorrentes ou demandas restritivas. Como sua aplicação implica considerar toda a cadeia de valor e o ciclo de vida do produto, o custeio alvo não será objeto de análise desta pesquisa.

\section{METODOLOGIA DA PESQUISA}

Para obtenção dos dados, optou-se por uma pesquisa exploratória e qualitativa, realizada por meio de um estudo de caso. De acordo com Martins (2004), a pesquisa exploratória privilegia a análise de micro processos através de um exame intensivo dos dados. Para Cervo e Bervian (1996), a pesquisa exploratória é responsável por observar, registrar, analisar e correlacionar os fatos ou fenômenos sem manipulá-los.

Yin (2005) sugere o estudo de caso como estratégia ideal quando o problema de pesquisa apresenta questões do tipo "como" e "por que", e cujo poder diferenciador sobre as demais metodologias está na sua capacidade de lidar com uma ampla variedade de evidências - documentos, artefatos, entrevistas e observações.

A organização pesquisada é um hospital filantrópico de alta complexidade, de porte médio com 160 leitos, estabelecido em Santa Catarina, considerado um centro de referência em medicina e gestão no Estado. A escolha da instituição foi intencional devido ao fato desta organização hospitalar possuir um sistema de custos implantado que é considerado um benchmarking neste setor. É relevante mencionar que o sistema de custo focalizado na pesquisa, ainda que desenvolvido no hospital pesquisado, está atualmente disponível e em uso em mais de cem hospitais no Brasil, públicos e privados, com e sem fins lucrativos.

A pesquisa foi realizada por meio de entrevista semi-estrutura, conduzida a partir de um roteiro de orientação. Segundo Triviños (1987), a entrevista semi-estruturada é a 
Uso do Custeio por Absorção e do Sistema RKW para gerar informações gerenciais: Um estudo de caso em hospital Ilse Maria Beuren, Nair Fernandes Schlindwein

que parte de certos questionamentos básicos, apoiados no referencial teórico e hipóteses, que provocam novos questionamentos no transcorrer da entrevista e influenciam a elaboração do conteúdo da pesquisa.

Não se seguiu rigorosamente a ordem do roteiro para deixar o entrevistado livre e se aprofundar em questões que considera relevantes. Todavia, todos os pontos estabelecidos no roteiro inicial foram abordados. A entrevista teve duração de duas horas e meia com o responsável da área de custos do hospital, que participou do desenvolvimento e implantação do sistema de custo.

Também utilizou-se a técnica de observação. Sobre o método observacional, Fachin (2001) adverte que o observador deve reunir certas condições, entre as quais dispor dos órgãos sensoriais em perfeito estado, de um bom preparo intelectual, aliado à sagacidade, curiosidade, persistência, perseverança, paciência e um grau elevado de humildade. Neste sentido, foi realizada pesquisa no sistema de custo e em documentos gerenciais dele extraídos, referentes ao mês de novembro de 2007.

Para análise dos dados utilizou-se abordagem predominantemente qualitativa. Segundo Richardson (1999), o método qualitativo caracteriza-se pelo não emprego de instrumental estatístico como base no processo de análise de um problema.

Embora tenha sido adotado o rigor científico necessário em pesquisa dessa natureza, ressalta-se o fato do estudo se circunscrever a um único objeto ou fenômeno. Esta estratégia de pesquisa se constitui em uma limitação, uma vez que seus resultados não podem ser generalizáveis a outros objetos ou fenômenos, dado as particularidades do sujeito da pesquisa.

\section{DESCRIÇÃO E ANÁLISE DO ESTUDO DE CASO}

O sistema de custos implantado no Hospital pesquisado foi desenvolvido internamente com a contratação de uma empresa terceirizada. Trata-se de um módulo do sistema Enterprise Resource Planning (ERP), ou sistema de gerenciamento de recursos, totalmente integrado com todas as áreas do hospital. O sistema de custos está fundamentado no custeio por absorção, aliado ao sistema RKW. 
Uso do Custeio por Absorção e do Sistema RKW para gerar informações gerenciais: Um estudo de caso em hospital Ilse Maria Beuren, Nair Fernandes Schlindwein

No sistema de custos objeto de estudo foi adotado o modelo clássico de apropriação dos custos por centro de custo, identificando-os de acordo com sua natureza: fixos, variáveis, diretos e indiretos. A apropriação dos custos para os centros de custos é feita por critérios de distribuição utilizando a metodologia RKW, conforme exemplificado no Quadro 1.

\begin{tabular}{|c|c|c|}
\hline Centro de Custo & Natureza do Custo & Critério de distribuição ou rateio \\
\hline Administração Geral & Despesa Administrativa & Pró-rata de custo fixo \\
\hline Custos & Despesa Administrativa & Pró-rata de custo fixo \\
\hline Pessoal/RH & Despesa Administrativa & Número de funcionários p/ CC \\
\hline Contabilidade & Despesa Administrativa & Pró-rata de custo fixo \\
\hline Qualidade & Despesa Administrativa & Pró-rata de custo fixo \\
\hline Financeiro & Despesa Administrativa & Pró-rata de custo fixo \\
\hline Informática & Despesa Administrativa & Pró-rata de custo fixo \\
\hline Compras & Despesa Administrativa & Pró-rata de custo variável \\
\hline Central Material Esterilizado & Apoio direto & Quantidade de pacotes esterilizados \\
\hline Almoxarifado/Farmácia & Apoio indireto & № de itens atendidos por CC \\
\hline Manutenção & Apoio indireto & Horas trabalhadas por CC \\
\hline Lavanderia & Apoio variável & Kgs de roupa lavada \\
\hline Higienização & Apoio variável & Horas trabalhadas por CC \\
\hline Nutrição & Apoio variável & № de refeições servidas \\
\hline Faturamento & Despesa Administrativa & Pró-rata de faturamento por setor produtivo \\
\hline
\end{tabular}

Quadro 1 - Critérios de distribuição dos custos indiretos das áreas de apoio e administrativo Fonte: adaptado de dados primários do Hospital.

A metodologia RKW prevê a alocação dos custos utilizando uma sequência hierárquica de centros de custos, ou seja, em cascata, até que todos os custos sejam alocados para as áreas produtivas e não reste nenhum custo alocado para áreas não produtivas.

No hospital, a distribuição ou rateio dos custos são calculados a partir da natureza de todos os custos fixos ou variáveis, identificados no período, ponderados pelo custo fixo, variável ou receita do respectivo centro de custo. Portanto, os custos identificados em um determinado centro de custo são classificados de acordo com sua natureza, conforme demonstrado no Quadro 2, e alocados para os setores produtivos. 
Uso do Custeio por Absorção e do Sistema RKW para gerar informações gerenciais: Um estudo de caso em hospital Ilse Maria Beuren, Nair Fernandes Schlindwein

\begin{tabular}{|c|c|c|}
\hline Centro de Custo & Natureza do Custo & Apropriação \\
\hline \multirow{3}{*}{ Centro Cirúrgico } & Custo Variável & Direto \\
\cline { 2 - 3 } & Custo Fixo & $\begin{array}{c}\text { Direto com base em critérios de rateios fixos. Ex.: } \\
\text { energia elétrica, água }\end{array}$ \\
\cline { 2 - 3 } & Custo dos Centros de Apoio & Por meio de critérios de rateio (Quadro 1) \\
\cline { 2 - 3 } & Custos Administrativos & Por meio de critérios de rateio (Quadro 1) \\
\hline
\end{tabular}

Quadro 2 - Classificação hierárquica dos custos para os centros de custo produtivos Fonte: adaptado de dados primários do Hospital.

A metodologia de apropriação de custos implantada prevê o agrupamento dos materiais consumidos por meio de classificação segundo a qual somente são apropriados diretamente os custos variáveis, ou seja, aqueles aplicados diretamente aos centros de custo produtivos, conforme demonstrado no Quadro 3. Portanto, neste sistema somente setores produtivos apresentam custos variáveis.

\begin{tabular}{|c|c|}
\hline Grupo de Materiais & Natureza do Custo \\
\hline Combustíveis e Lubrificantes & Custo Fixo \\
\hline Gasoterapia & Custo Variável \\
\hline Gêneros Alimentícios & Custo Fixo \\
\hline Impressos e materiais de expediente & Custo Fixo \\
\hline Materiais de Diagnóstico por Imagem & Custo Variável \\
\hline Materiais de manutenção e conservação & Custo Fixo \\
\hline Materiais Hospitalares & Custo Variável \\
\hline Materiais de Higiene e Limpeza & Custo Fixo \\
\hline Medicamentos & Custo Variável \\
\hline Órteses, próteses e materiais especiais (OPME) & Custo Variável \\
\hline Serviços de terceiros & Custo Fixo \\
\hline Uniformes e E.P.I. & Custo Fixo \\
\hline
\end{tabular}

Quadro 3 - Classificação dos materiais

Fonte: adaptado de dados primários do Hospital.

A hierarquia utilizada prevê ainda que somente os custos de gasoterapia, materiais de diagnóstico por imagem, materiais hospitalares, medicamentos e OPME são variáveis e que possuem uma receita associada, sendo sua apropriação direta para os centros de custo produtivos onde foram consumidos, a partir do custo médio de estoque. Os demais custos, considerados fixos, são alocados aos setores produtivos por critérios de rateio.

A alocação dos custos diretos é realizada a partir do atendimento da prescrição médica ou de enfermagem, que identifica o paciente e o setor em que está acomodado, 
Uso do Custeio por Absorção e do Sistema RKW para gerar informações gerenciais: Um estudo de caso em hospital Ilse Maria Beuren, Nair Fernandes Schlindwein

alocando tanto os custos quanto as respectivas receitas. Os materiais diretos não vinculados à prescrição médica ou de enfermagem são alocados aos setores produtivos com base no atendimento da requisição de materiais feita aos locais de estoque.

Cabe ressaltar que a operacionalização deste processo com as respectivas alocações dos custos é facilitada pelo sistema informatizado de ERP que integra todo o Hospital, identificando em tempo real as movimentações de materiais vinculadas às suas respectivas origens.

Por sua vez, a alocação dos custos fixos por meio de critérios de rateio ou distribuição produz uma taxa de custo em unidades monetárias $(R \$)$, que inclui todos os custos fixos demonstrados no Quadro 3 e que são exemplificados na Tabela 1. 
Tabela 1 - Alocação de custos fixos para um setor produtivo

\begin{tabular}{|c|c|c|}
\hline Descrição Custo $\mathbf{R} \$$ & Taxa & Custo $(\mathbf{R} \$)$ \\
\hline Serviços de terceiros & $9.927,16$ & 11,1468 \\
\hline Assessoria Jurídica & $1.015,23$ & 1.1400 \\
\hline Contratos manutenção & $4.087,21$ & 45.894 \\
\hline Serviços administrativos & 574,24 & 0,6448 \\
\hline Serviços manut./reparos & $1.062,95$ & 1,1935 \\
\hline Serviços Manutenção corretiva & $3.187,53$ & 3,5791 \\
\hline Encargos Sociais & $12.676,02$ & 14,2332 \\
\hline FGTS & $3.356,30$ & 3,7686 \\
\hline PIS & 457,35 & 0,5135 \\
\hline Provisão Férias & $4.339,06$ & 4,8721 \\
\hline Provisão Encarg.Férias & 347,08 & 0,3897 \\
\hline Prov. Encarg. $13^{\circ}$ Salário & 309,34 & 0,3473 \\
\hline Provisão 13 o Salário & $3.866,89$ & 4,3420 \\
\hline Depreciações e Amortizações & $21.437,60$ & 24,0714 \\
\hline Outros Custos/Despesas & $2.274,16$ & 2,5536 \\
\hline Correios e Telégrafos & 64,90 & 0,0729 \\
\hline $\begin{array}{l}\text { Provisão para perda de processos } \\
\text { cíveis }\end{array}$ & $2.000,00$ & 2,2457 \\
\hline Seguros Funcionários Afastados & 209,26 & 0,2350 \\
\hline Proventos (Sal./Orden.) & $41.207,92$ & 46,2706 \\
\hline Benefícios & $5.627,15$ & 6,3185 \\
\hline Seguro Saúde e Vida em Grupo & $2.882,38$ & 3,2365 \\
\hline Uniformes e EPI & $2.210,30$ & 2,4819 \\
\hline Vale Transporte & 534,47 & 0,6001 \\
\hline Material de Consumo & $15.999,60$ & 17,9653 \\
\hline Impressos e Material de Expediente & 758,34 & 0,8515 \\
\hline Manutenção Predial & 47,57 & 0,0534 \\
\hline Materiais de Manutenção/Reposição & $12.642,53$ & 14,1958 \\
\hline Material de Higiene e Limpeza & $2.551,16$ & 2,8646 \\
\hline Energia/Água/Telefone & $7.205,78$ & 8,091 \\
\hline Água & 720,26 & 0,8087 \\
\hline Energia Elétrica & $6.036,20$ & 6,7778 \\
\hline Telefone & 449,32 & 0,5045 \\
\hline $\begin{array}{l}\text { Gêneros Alimentícios } \\
\text { Transferência Recebida }\end{array}$ & 875,86 & 0,9835 \\
\hline de Apoio Variável & $28.487,70$ & 31,9876 \\
\hline Higienização & $10.427,13$ & 11,7082 \\
\hline Nutrição Clínica & 15,29 & 0,0172 \\
\hline Processamento Roupas & $17.830,35$ & 20,0210 \\
\hline Serviço de Nutrição - Distribuição & 36,03 & 0,0405 \\
\hline Serviço de Nutrição - Produção & 210,87 & 0,2368 \\
\hline $\begin{array}{l}\text { SNP - Dedução da Receita Refeitório } \\
\text { Transf. Recebida Custo Direto }\end{array}$ & $-31,97$ & 0,0359 \\
\hline Serviço - SRPA & $29,132,15$ & 32,7113 \\
\hline
\end{tabular}

Descrição Custo R\$
Transferência de Despesa
Administrativa
Administração Geral
Agendamento e Autorizações
Assistência Social
Auditoria de Contas
Capacitação e Desenvolvimento
Central de Cópias
Centro de Estudos
CIPA

Clínica Pastoral

Comercial e Marketing Compras

Contabilidade

Custos

Educação Continuada

Faturamento

Financeiro

Funcionários Afastados

Gerência Financeira

Gerência de Negócios

Gerência Médica

Informática

Pessoal

Qualidade

Recepção Internação

Recepção de Visitas - Entrada

Principal

SAC

Same

Segurança e Medicina do Trabalho

Subestação Elétrica

Telefonia

Transporte

Transferência Recebida de Apoio Indireto

\section{Almoxarifado \\ Caldeira \\ C.C.I.H}

Farmácia Central

Gerência Assistencial

Manutenção Clínica Hospitalar

Transferência Recebida Apoio Direto

Central de Material Esterilizado Farmácia Centro Cirúrgico

\begin{tabular}{|c|c|}
\hline Taxa & Custo $(R \$)$ \\
\hline $96.060,08$ & 106,739 \\
\hline $9.317,27$ & 10,462 \\
\hline $1.996,84$ & 2,2422 \\
\hline $1.653,64$ & 1.8568 \\
\hline $1.795,02$ & 2,0156 \\
\hline $2.478,28$ & 2,7828 \\
\hline 752,82 & 0,8453 \\
\hline 229,73 & 0,258 \\
\hline 149,8 & 0,1682 \\
\hline $2.027,19$ & 2,2762 \\
\hline $5.216,49$ & 17,0860 \\
\hline $5.358,67$ & 6,0170 \\
\hline $2.059,52$ & 2,3125 \\
\hline 794,65 & 0,8923 \\
\hline $1.273,58$ & 1,4300 \\
\hline $5.587,81$ & 6,2743 \\
\hline $2.606,77$ & 2,9270 \\
\hline 417,77 & 0,4691 \\
\hline $2.168,06$ & 2,4344 \\
\hline $1.950,39$ & 2,1900 \\
\hline $3.004,36$ & 3,3735 \\
\hline $9.673,68$ & 10,8622 \\
\hline $2.119,15$ & 2,3795 \\
\hline $2.356,51$ & 2,6460 \\
\hline $6.734,13$ & 7,5615 \\
\hline $1.482,39$ & 1,6645 \\
\hline $2.351,39$ & 2,6403 \\
\hline 748,15 & 0,8401 \\
\hline $5.080,10$ & 5,7042 \\
\hline $1.217,53$ & 1,3671 \\
\hline $1.448,54$ & 1,6265 \\
\hline $1.009,85$ & 1,1339 \\
\hline $8.228,65$ & 31,6968 \\
\hline 476,76 & 0,5353 \\
\hline 299,14 & 0,3359 \\
\hline $1.615,81$ & 1,8143 \\
\hline 718,95 & 0,8073 \\
\hline $1.565,03$ & 1,7573 \\
\hline $3.552,96$ & 26,4466 \\
\hline $33.722,02$ & 37,8650 \\
\hline $21.116,66$ & 23,711 \\
\hline $2.605,36$ & 14,1540 \\
\hline 361.58 & 372.6336 \\
\hline
\end{tabular}

Fonte: adaptado de dados primários do Hospital 
Uso do Custeio por Absorção e do Sistema RKW para gerar informações gerenciais: Um estudo de caso em hospital Ilse Maria Beuren, Nair Fernandes Schlindwein

Esta metodologia permite identificar o custo de uma unidade produtiva, no exemplo, de uma hora, ou de outra unidade de medida conforme a produção do setor, a partir da transferência de todos os custos fixos, diretos e indiretos. Os custos fixos são alocados de forma direta e sem sofrer rateio, os custos de apoio e administrativos são apropriados com base em critérios de distribuição. Cabe ressaltar que o uso desta metodologia se traduz em custos diferentes para o mesmo serviço fornecido aos diversos centros de custo, em função de sua estrutura e utilização.

A metodologia exposta é aplicada em todas as áreas produtivas, com exceção dos serviços fornecidos pela Clínica de Diagnóstico por Imagem. Neste caso, além das transferências de custos fixos, o custo do serviço prestado inclui a proporção dos materiais de imagem, como filmes utilizados nos exames, sendo o custo convertido para CH's (coeficientes de honorários) devido ao reembolso deste serviço ser realizado nesta mesma unidade.

A principal diferença na apuração do custo dos produtos de diagnóstico por imagem é sua elaboração a partir de uma ficha técnica que contém informações sobre: a) consumo de material; b) tempo de realização; e c) equipamentos utilizados no serviço. A definição do custo do tempo e dos serviços aplicados é apurada pelos custos médios históricos identificados e dos materiais pelo custo médio de estoque.

O tratamento do custo dos demais serviços de diagnósticos terapêuticos, fornecidos pelo laboratório de análises clínicas e pelos serviços médicos, são repassados integralmente. Ou seja, para estes serviços a receita é igual ao custo.

A sequência de alocação dos custos pode ser visualizada de forma resumida na Figura 1. 
Uso do Custeio por Absorção e do Sistema RKW para gerar informações gerenciais: Um estudo de caso em hospital Ilse Maria Beuren, Nair Fernandes Schlindwein
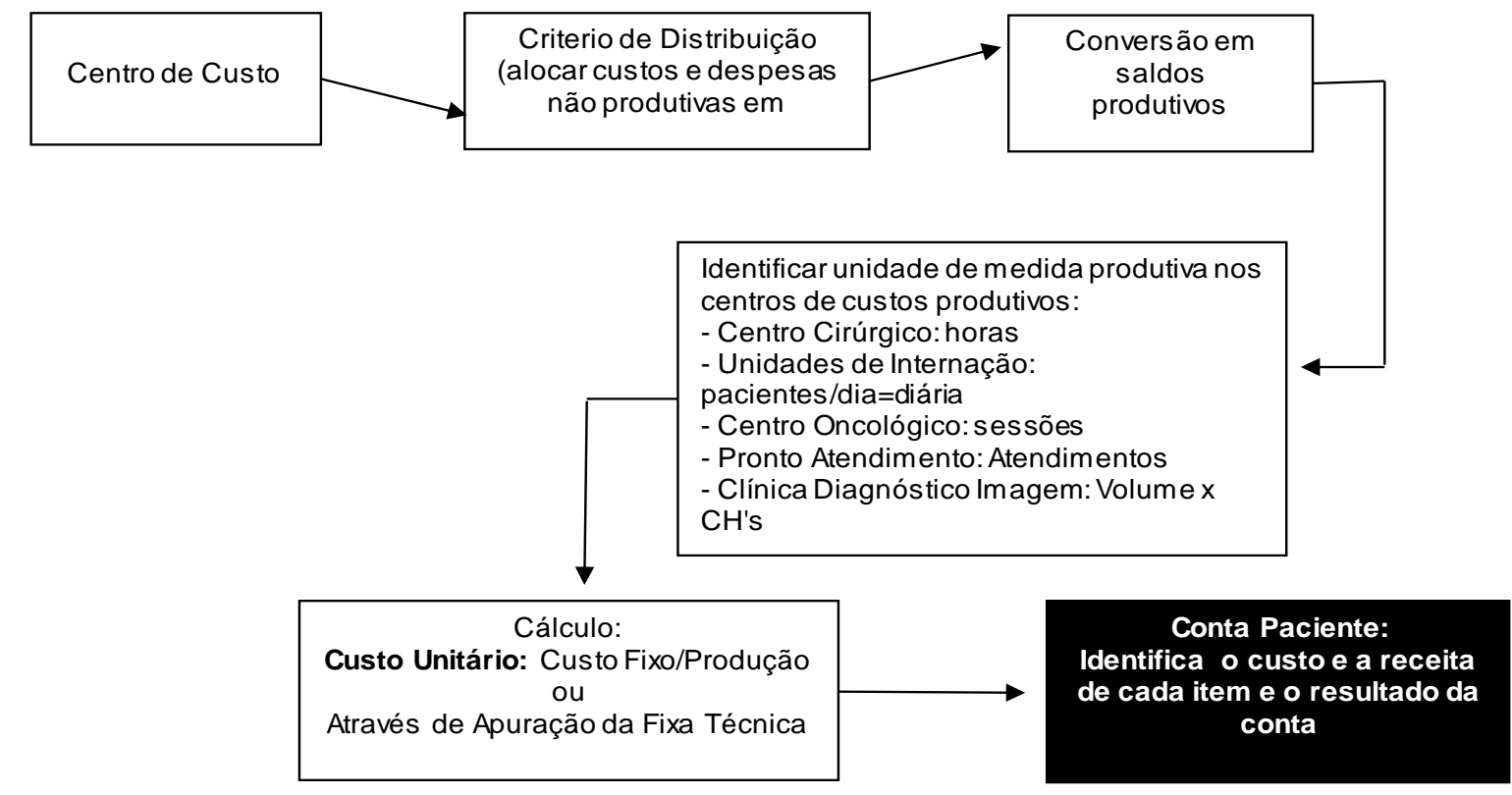

Figura 1: Sequência de alocação e formação dos custos no Hospital Fonte: elaboração própria a partir de dados fornecidos pelo Hospital.

O sistema de custos implementado no Hospital permite a apuração e o acompanhamento mensal dos custos dos serviços. Os resultados por paciente, procedimento, material e centro de custo, são comparados com as receitas efetivas. Portanto, o sistema propicia geração de informações relevantes para o processo decisório, conforme demonstrado na Tabela 2. 


\section{Uso do Custeio por Absorção e do Sistema RKW para gerar informações gerenciais: Um estudo \\ de caso em hospital}

Ilse Maria Beuren, Nair Fernandes Schlindwein

Tabela 2 - Apuração do resultado da conta paciente

\begin{tabular}{|c|c|c|c|c|c|c|c|}
\hline $\begin{array}{l}\text { Centro de Custo / } \\
\text { Descrição Materiais }\end{array}$ & Receita & Custo & Resultado & $\begin{array}{l}\text { Centro de Custo / } \\
\text { Descrição Materiais }\end{array}$ & Receita & Custo & Resultado \\
\hline Centro Cirúrgico & 355,48 & 403,94 & $-48,46$ & $\begin{array}{l}\text { Unidade Internação - } \\
\text { Enfermaria }\end{array}$ & 565,29 & 812,04 & $-246,75$ \\
\hline Materiais & 106,64 & 35,03 & 71,61 & Diárias & 284,96 & 720,00 & $-435,04$ \\
\hline Agulha descartável $30 \times 07$ & 0,19 & 0,07 & 0,12 & Enfermaria c/ banheiro & 284,96 & 720,00 & $-435,04$ \\
\hline Agulha descartável $40 \times 12$ & 0,55 & 0,23 & 0,32 & Materiais & 153,62 & 28,15 & 125,47 \\
\hline Seringa descartável $10 \mathrm{~mL}$ & 0,79 & 0,27 & 0,52 & $\begin{array}{c}\text { Agulha Descartável } 25 x \\
07\end{array}$ & 0,16 & 0,07 & 0,09 \\
\hline Seringa descartável $20 \mathrm{~mL}$ & 3,22 & 0,76 & 2,46 & $\begin{array}{l}\text { Agulha Descartável } 30 \mathrm{x} \\
07\end{array}$ & 0,57 & 0,22 & 0,35 \\
\hline $\begin{array}{c}\text { Catéter intravenoso periférico no } \\
18\end{array}$ & 12,67 & 2,11 & 10,56 & $\begin{array}{l}\text { Agulha Descartável } 40 x \\
12\end{array}$ & 1,09 & 0,47 & 0,62 \\
\hline Luva cirúrgica no 7,0 & 2,16 & 1,64 & 0,52 & Seringa Descartável 3mL & 1,21 & 0,41 & 0,80 \\
\hline Luva cirúrgica $n^{\circ}$ 8,0 & 2,16 & 1,65 & 0,51 & $\begin{array}{c}\text { Seringa Descartável } \\
10 \mathrm{~mL}\end{array}$ & 3,18 & 1,07 & 2,11 \\
\hline Atadura crepom $20 \mathrm{~cm}$ & 3,91 & 2,86 & 1,05 & $\begin{array}{l}\text { Catéter intravenoso } \\
\text { periférico } \mathrm{n}^{\circ} 20\end{array}$ & 12,67 & 2,55 & 10,12 \\
\hline Cord Clamp umbilical & 0,58 & 0,31 & 0,27 & $\begin{array}{l}\text { Catéter intravenoso } \\
\text { periférico no } 22\end{array}$ & 12,67 & 2,55 & 10,12 \\
\hline $\begin{array}{l}\text { Fita Micropore } 5,0 \mathrm{~cm} \times 10 \mathrm{~m} \\
(1000 \mathrm{~cm})\end{array}$ & 0,82 & 0,42 & 0,40 & Equipo polifix 2 vias & 9,43 & 2,23 & 7,20 \\
\hline Lâmina de bisturi no 21 & 2,53 & 0,82 & 1,71 & $\begin{array}{l}\text { Equipo eurofix compact } \\
\text { air } p / \text { bomba }\end{array}$ & 101,11 & 16,27 & 84,84 \\
\hline Equipo Intrafix microgotas & 12,28 & 2,09 & 10,19 & $\begin{array}{c}\begin{array}{c}\text { Sonda nasogástrica } \\
\text { no } 04 \text { curta }\end{array} \\
\end{array}$ & 1,89 & 0,59 & 1,30 \\
\hline Equipo polifix 2 vias & 9,43 & 2,23 & 7,20 & Equipo eurofix IL & 9,64 & 1,72 & 7,92 \\
\hline $\begin{array}{l}\text { Eletrodo descartável } \\
\text { adulto }\end{array}$ & 3,28 & 1,75 & 1,53 & Medicamentos & 125,91 & 63,38 & 62,53 \\
\hline Luva plástica EVA (Estéril) & 0,08 & 0,06 & 0,02 & $\begin{array}{c}\text { Soro glicosado } 5 \% \text { frasco } \\
\text { c/ } 500 \mathrm{Ml}\end{array}$ & 6,88 & 3,39 & 3,49 \\
\hline Pulseira identificação (mãe/filho) & 1,42 & 1,07 & 0,35 & $\begin{array}{l}\text { Água destilada estéril } \\
\text { ampola } \mathrm{c} / 10 \mathrm{~mL}\end{array}$ & 0,95 & 0,28 & 0,67 \\
\hline Álcool $70 \%$ almotolia c/ $100 \mathrm{~mL}$ & 0,02 & 0,01 & 0,01 & Sedalene cáps. & 1,96 & 1,42 & 0,54 \\
\hline Fio vicryl $0(\mathrm{~J} 370 \mathrm{H})$ & 30,76 & 10,28 & 20,48 & Kefazol 1g inj. & 17,84 & 3,94 & 13,90 \\
\hline Sonda $n^{\circ} 8$ asp. Traqueal & 1,06 & 0,37 & 0,69 & Methergin $0,125 \mathrm{mg} \mathrm{drg}$. & 1,54 & 1,26 & 0,28 \\
\hline Equipo eurofix IL & 9,64 & 1,72 & 7,92 & $\begin{array}{c}\text { Celestone soluspan } 6 \mathrm{mg} \\
\text { ampola } \mathrm{c} / 1 \mathrm{~mL}\end{array}$ & 27,39 & 15,29 & 12,10 \\
\hline $\begin{array}{l}\text { Gaze dobrada estéril } 13 \text { fios } \\
10 \mathrm{~cm} \mathrm{x}\end{array}$ & 4,55 & 2,08 & 2,47 & $\begin{array}{c}\text { Solução ringer c/ lactato } \\
\text { frasco c/ }\end{array}$ & 18,97 & 7,16 & 11,81 \\
\hline $\begin{array}{c}\text { Clorexidina degermante } \\
2 \% \text { solução }\end{array}$ & 4,54 & 2,23 & 2,31 & $\begin{array}{l}\text { Terbutil 0,5mg inj. Ampola } \\
\mathrm{c} / 1 \mathrm{~mL}\end{array}$ & 50,38 & 30,64 & 19,74 \\
\hline Medicamentos & 17,44 & 18,40 & $-0,96$ & $\begin{array}{l}\text { Serviços } \\
\end{array}$ & 0,80 & 0,51 & 0,29 \\
\hline $\begin{array}{l}\text { Soro glicosado } 5 \% \text { frasco } \\
\mathrm{c} / 250 \mathrm{~mL}\end{array}$ & 2,69 & 1,46 & 1,23 & $\begin{array}{c}\text { Oxigênio } 3 \mathrm{l} / \mathrm{m} \text { (valor por } \\
\text { minuto) }\end{array}$ & 0,8 & 0,51 & 0,29 \\
\hline $\begin{array}{c}\text { Soro fisiológico } 0,9 \% \text { frasco } \\
\mathrm{c} / 1000 \mathrm{~mL}\end{array}$ & 4,35 & 2,46 & 1,89 & Sala de Recuperação & 13,89 & 4,12 & 9,77 \\
\hline
\end{tabular}


Uso do Custeio por Absorção e do Sistema RKW para gerar informações gerenciais: Um estudo de caso em hospital Ilse Maria Beuren, Nair Fernandes Schlindwein

\begin{tabular}{|c|c|c|c|c|c|c|c|}
\hline $\begin{array}{c}\text { Água destilada estéril ampola } \\
\mathrm{c} / 20 \mathrm{~mL}\end{array}$ & 0,62 & 0,23 & 0,39 & Materiais & 1,06 & 0,39 & 0,67 \\
\hline $\begin{array}{l}\text { Água destilada estéril frasco } \\
\mathrm{c} / 500 \mathrm{~mL}\end{array}$ & 3,34 & 1,10 & 2,24 & $\begin{array}{l}\text { Agulha Descartável } 40 \mathrm{x} \\
12\end{array}$ & 0,27 & 0,12 & 0,15 \\
\hline $\begin{array}{c}\text { Adrenalina } 1 \mathrm{mg} \text { inj. Ampola } \\
\mathrm{c} / 1 \mathrm{~mL}\end{array}$ & 0,42 & 0,30 & 0,12 & $\begin{array}{c}\text { Seringa Descartável } \\
10 \mathrm{~mL}\end{array}$ & 0,79 & 0,27 & 0,52 \\
\hline $\begin{array}{c}\text { Soro fisiológico } 0,9 \% \text { frasco } \\
\mathrm{c} / 250 \mathrm{~mL}(\mathrm{p} /\end{array}$ & 2,29 & 0,95 & 1,34 & Medicamentos & 12,83 & 3,73 & 9,10 \\
\hline $\begin{array}{c}\text { Soro fisiológico } 0,9 \% \text { frasco } \\
\mathrm{c} / 100 \mathrm{~mL}\end{array}$ & 2,06 & 1,40 & 0,66 & $\begin{array}{l}\text { Soro glicofisiológico } \\
\text { frasco c/ } 500 \mathrm{~mL}\end{array}$ & 3,44 & 1,62 & 1,82 \\
\hline Xylocaína 2\% geléia seringa c/ $3 \mathrm{~g}$ & 1,67 & 10,50 & $-8,83$ & $\begin{array}{l}\text { Água destilada estéril } \\
\text { ampola } \mathrm{c} / 10 \mathrm{~mL}\end{array}$ & 0,47 & 0,14 & 0,33 \\
\hline Serviços & 0,80 & 0,51 & 0,29 & Kefazol 1g inj. & 8,92 & 1,97 & 6,95 \\
\hline Oxigênio $3 \mathrm{l} / \mathrm{m}$ (valor por minuto) & 0,80 & 0,51 & 0,29 & Methergin $0,125 \mathrm{mg}$ drg. & 0,00 & 0,00 & 0,00 \\
\hline Taxas & 230,60 & 350,00 & $-119,40$ & & & & \\
\hline Taxa Sala Cirúrgica T5 (2:00 hora) & 230,60 & 350,00 & $-119,40$ & & & & \\
\hline Ultra-som & 226,48 & 205,43 & 21,05 & & & & \\
\hline Sadts & 226,48 & 205,43 & 21,05 & & & & \\
\hline U.S. Obstétrica & 36,59 & 36,95 & $-0,36$ & & & & \\
\hline $\begin{array}{c}\text { U.S. Estudo de } 3 \text { ou mais } \\
\text { vasos }\end{array}$ & 155,74 & 168,48 & $-12,74$ & & & & \\
\hline $\begin{array}{l}\text { U.S. Estudo Doppler } \\
\text { Colorido - Acresc. }\end{array}$ & 34,15 & 0,00 & 34,15 & & & & \\
\hline Total Conta Enfermaria & & & & & $1.161,14$ & $1.425,53$ & $-264,39$ \\
\hline Total Conta Apartamento & & & & & $1.715,38$ & $2.145,53$ & $-430,15$ \\
\hline
\end{tabular}

Fonte: adaptado de dados primários do Hospital.

Para estabelecer os preços de procedimentos, o que se faz necessário para pacientes particulares e quando da renegociação dos contratos com os convênios, a sistemática utilizada é a identificação do custo médio histórico sobre o qual é aplicada a política de preços.

Cabe ressaltar que para muitos convênios a tabela de preços é fixa, ou seja, os preços não são determinados pelo Hospital a partir de seus custos. Nesses casos é ainda mais relevante a apuração do custo unitário para compará-lo à receita, a fim de identificar necessidades de ação em caso de déficit, como a renegociação dos preços ou a redução dos custos fixos. 
Uso do Custeio por Absorção e do Sistema RKW para gerar informações gerenciais: Um estudo de caso em hospital Ilse Maria Beuren, Nair Fernandes Schlindwein

\section{CONCLUSÃO}

A apuração e o controle dos custos são relevantes para qualquer organização, com destaque para as organizações hospitalares, que enfrentam usualmente limitações em relação aos recursos disponíveis. A literatura aponta com frequência vantagens do uso de diferentes sistemas de custos para organizações de serviço e especialmente de saúde, contudo sem ter validado esses modelos em uma organização hospitalar completa e identificado seus reais e efetivos benefícios.

Nesse sentido, o estudo objetivou demonstrar o uso do custeio por absorção aliado ao sistema RKW para gerar informações gerenciais em uma organização hospitalar, dispensando assim um sistema paralelo de custeio e os custos a ele relacionados para atendimento dos preceitos legais. A pesquisa foi conduzida a partir de uma entrevista no mês de novembro de 2007 com o responsável de custos do hospital e de análise documental.

O sistema de custo implantado no hospital pesquisado, com base em um método aceito pelo fisco brasileiro, fornece informações gerenciais, com tempo de resposta e detalhamento aceitável, que permite identificar os custos de cada material e serviço utilizado e compará-lo com a respectiva receita. Esse sistema, fundamentado no custeio por absorção aliado ao sistema RKW, permite inclusive a implantação de uma gestão através do custo alvo ou custo meta, visto que cada serviço tem uma origem de receita identificada e/ou negociada, facilitando a identificação e análise do custo meta.

É importante ressaltar que o sistema de custo do hospital está fortemente sustentado pela informatização do processo, que permite identificar em tempo real as atividades realizadas em cada centro de custo, identificando seus destinatários ou consumidores, facilitando o uso do sistema RKW. Todavia, para custos fixos indiretos, como a energia elétrica, água e combustível, é imprescindível a verificação periódica dos critérios de distribuição. Devido à dinâmica na atividade hospitalar, a distribuição da energia elétrica, por exemplo, a cada novo equipamento comprado e/ou disponibilizado para um determinado centro de custo, é necessário que as cargas de distribuição sejam revistas para que a apropriação do custo seja a mais real possível. 
Uso do Custeio por Absorção e do Sistema RKW para gerar informações gerenciais: Um estudo de caso em hospital Ilse Maria Beuren, Nair Fernandes Schlindwein

Embora o uso de um sistema de custeio baseado em atividades seja amplamente recomendado pela literatura para empresas de serviços e as vantagens possam ser facilmente visualizadas em ambientes hospitalares, algumas dificuldades devem ser consideradas. Além do custo de sua implantação e da necessidade da manutenção de um sistema de custeio duplo, destaca-se a dificuldade em identificar detalhadamente as atividades envolvidas em cada serviço desenvolvido. As atividades variam constantemente e possuem ramificações complexas se analisada de forma integrada no amplo e complexo contexto hospitalar.

Assim conclui-se que, considerando a necessidade de identificação dos custos dos serviços prestados, bem como dos materiais utilizados, o sistema de custo implantado no hospital pesquisado atende satisfatoriamente a demanda por informações gerenciais, propiciando também tempo de resposta adequado. $O$ adequado uso do sistema de custo, bem como a correta divulgação de sua aplicação é um passo importante para a profissionalização do ambiente hospitalar e a adequada gestão dos recursos consumidos.

Recomenda-se para futuras pesquisas um estudo comparativo entre os resultados da utilização do custeio por absorção aliado ao sistema RKW e os resultados que se obteria com a aplicação de outros métodos de custeio à mesma situação, por exemplo o custeio baseado em atividades. Também recomenda-se pesquisa que utilize o custo meta para análise da viabilidade de convênios, utilizando diferentes métodos de custeio e depois faça comparação dos resultados.

\section{REFERÊNCIAS}

ABBAS, K. (2001). Gestão de custos em organizações hospitalares. Florianópolis, SC. (Dissertação de mestrado). Universidade Federal de Santa Catarina - EPS/UFSC, 155 p.

ANTHONY, Robert N. e GOVINDARAJAN, V. (2002). Sistemas de controle gerencial. São Paulo, Atlas. 1019 p. 
Uso do Custeio por Absorção e do Sistema RKW para gerar informações gerenciais: Um estudo de caso em hospital Ilse Maria Beuren, Nair Fernandes Schlindwein

ATKINSON, A.; BANKER, R. D.; KAPLAN, R. S, e YOUNG, S. M. (2000). Contabilidade gerencial. São Paulo, Atlas, 633 p.

BORNIA, A. C. (2002). Análise gerencial de custos: aplicação em empresas modernas. Porto Alegre, Bookman, $203 \mathrm{p}$.

CERVO, A. e BERVIAN, A. (1996). Metodologia científica: para uso dos estudantes universitários. (4 ed.). São Paulo, McGraw-Hill do Brasil, 209 p.

COOPER, R. e SLAGMULDER, R. (1997). Factors influencing the target costing process: lessons from japanese practice. Disponível em: $<w w w$. feb.ugent.be/fac/research/wp/papers/up_97.30>. Acesso em: 13/jan/2008.

DALMÁCIO, F. Z. e REZENDE, A. J. e AGUIAR, A. B. (2006). Uma aplicação do TimeDriven ABC Model no setor de serviço hospitalar: a nova abordagem do ABC proposta por Kaplan e Anderson. In: ENANPAD, 30. Salvador. Anais... Rio de Janeiro: ANPAD.

DUCATI, E. (2006). O custeio-meta e o custeio variável: é possível essa integração? In: ENANPAD, 30. Salvador. Anais... Rio de Janeiro: ANPAD.

FACHIN, O. (2001). Fundamentos de metodologia. São Paulo, Saraiva, 200 p.

FREGA, J. R., LEMOS, I. S. e SOUZA, A. (2007). Relação dinâmica entre as estratégias competitivas e os sistemas de gestão de custos: um estudo de caso. In: ENANPAD, 31. Rio de Janeiro. Anais... Rio de Janeiro: ANPAD.

HORNGREN, C. T.; FOSTER, G. e DATAR, S. M. (2000). Contabilidade de custos. (9 ed.). Rio de Janeiro, LTC, $717 \mathrm{p}$.

HORNGREN, C. T.; SUNDEM, G. L. e STRATTON, W. O. (2004). Contabilidade gerencial. (12 ed.). São Paulo, Pearson Prentice Hall, 560 p.

KAPLAN, R. e COOPER, R. (1998). Custo e desempenho. São Paulo, Futura, 376 p.

KAPLAN, R. S. e ANDERSON, S. R. (2004). Time-driven activity-based-costing. Havard Business Review, 320 p.

MARTINS, E. (2003). Contabilidade de custos. (9 ed.). São Paulo, Atlas, 370 p.

MARTINS, H. H. T. S. (2004). Metodologia qualitativa de pesquisa. Educação e Pesquisa, 30(2): 289-300, maio/ago.

MATOS, J. M. (2008). Abordagem alternativa ao time-driven ABC model. Disponível em: <http://www.jmdois.com.br/home/an_txt21.htm>. Acesso em: 13/jan/2008. 
Uso do Custeio por Absorção e do Sistema RKW para gerar informações gerenciais: Um estudo de caso em hospital Ilse Maria Beuren, Nair Fernandes Schlindwein

MATTOS, J. G. (2001). Modelo implantado no HU/UFSC. Disponível em: <http://www.gea.org.br/scf/plano.html>. Acesso em: 14/jan/2008.

MUCCINI, R. L.; BRUNI, A. L. e MAC-ALLISTER, M. (2006). Gerenciando custos, informações e sistemas: o caso do Hospital Santo Amaro, HSA. In: ENANPAD, 30. Salvador. Anais...Rio de Janeiro, ANPAD.

OKAZAKI, R. e ESCRIVÃO JR, Á. (2007). Identificação de ineficiências na cadeia de valor da saúde, a partir da análise da gestão de compras de quatro hospitais privados do município de São Paulo. In: XXXI ENANPAD, Rio de Janeiro. Anais... Rio de Janeiro: ANPAD.

Organização Pan-Americana da Saúde - OPAS. (2004). A transformação da gestão de hospitais na América Latina e Caribe. Brasília, OPAS/OMS.

RICHARDSON, R.J. (1999). Pesquisa social: métodos e técnicas. (3 ed.). São Paulo, Atlas, $389 \mathrm{p}$.

ROCHA, W. et al. (1999). Custeio-alvo: target costing. Revista da Associação Brasileira de Custos. São Leopoldo/RS. 1(1):83-94.

SAKURAI, M. (1997). Gerenciamento integrado de custos. São Paulo, Atlas, 279 p.

SHANK, J. K. e GOVINDARAJAN, V. (1997). A revolução dos custos: como reinventar e redefinir sua estratégia de custos para vencer em mercados crescentemente competitivos. (2 ed.). Rio de Janeiro, Campus, $341 \mathrm{p}$.

SOUZA, A. A.; SOUZA, N. C.; RAIMUNDINI, S. L.; SILVA, F. F. e VALVERDE, E. T. (2007). Modelagem do custeio baseado em atividades para farmácias hospitalares. In: ENANPAD, 31, Rio de Janeiro. Anais...Rio de Janeiro: ANPAD.

SOUZA, A. e CLEMENTE, A. (1998). Contextos, paradigmas e sistemas de custeio. In: Congresso Brasileiro de Gestão Estratégica de Custos, 5, Fortaleza. Anais...São Leopoldo/RS.

STRUETT, M. A. M.; SOUZA, A. A. e RAIMUNDINI, S. L. (2006). Aplicação do custeio baseado em atividades: estudo de caso de um laboratório de análises clínicas. In: Congresso Brasileiro de Custos, 13. Belo Horizonte. Anais...São Leopoldo/RS.

TRIVIÑOS, A. N. S. (1987). Introdução à pesquisa em ciências sociais: a pesquisa qualitativa em educação. São Paulo, Atlas, 175 p. 
Uso do Custeio por Absorção e do Sistema RKW para gerar informações gerenciais: Um estudo de caso em hospital Ilse Maria Beuren, Nair Fernandes Schlindwein

YIN, R. K. (2005). Estudo de caso: planejamento e métodos. (3 ed.). Porto Alegre, Bookman, $254 \mathrm{p}$.

YU-LEE, R. T. (2003). É preciso corrigir o custeio-alvo? HSM Management, 37:126-132, mar./abr.

Data de Submissão: 12/06/2008

Data de Aceite: 17/07/2008 